\title{
OBSERVATIONS ON SERIOUS DISTURBANCES \\ OF WATER AND ELECTROLYTE METABOLISM IN PATIENTS WITH TERMINAL ILEOSTOMIES
}

\author{
By A. O. Wilson, B.Sc., M.B., Ch.B., F.R.C.S.E. \\ From The Department of Surgery, Postgraduate Medical School of London
}

The management of mechanical complications which may accompany ileostomy has been well described (Warren and McKittrick, 195I ; Lahey, 195 I, I950a, I95ob; Hardy et al., 1949; Cave, 1946; Cave and Nickel, 1940). Information is not readily available about the management of the fluid and electrolyte exchange in patients with recent ileostomies. The various aspects of electrolyte exchange in such cases mentioned in the literature are as follows:

Extrarenal loss of sodium in excess of chloride; treatment with sodium chloride and sodium bicarbonate (Welch et al., 1937).

Fixed base loss in ileostomy fluid in excess of fixed acids ; replacement based on urinary chloride concentration (Coller and Maddock, 1940).

Circulatory collapse due to greater loss of fixed base and risk of sodium depletion (Nadal et al., 194I ; Randall et al., 1950).

Salt depletion (Cave and Nickel, 1940; Cave, 1946; Hardy et al., I949).

Chloride depletion (Ferguson and Welty, 1947; Michael, r95I).

Potassium depletion in patients who have diarrhoea and intestinal fistulae (Darrow, 1945; Blixenkrone-M $\phi$ ller, I95०; Lockwood and Randall, 1949).

Depletion of potassium, water and sodium (Counsell and Goligher, 1952).

Our experience has shown that on occasion sodium administration is essential in the aftertreatment of patients with ileostomies and evidence will be presented to show how the water and sodium depletion which may affect such patients may prove extremely serious and how they may be remedied.

\section{Material and Methods}

Five patients were studied, four suffering from ulcerative colitis and one from megacolon. Total colectomy with terminal ileostomy was performed in all five cases.

Urine was collected in 24-hour samples from 8 a.m. daily and was analyzed for sodium and potassium by an internal standard flame photometer and for chlorides by Sendroy's method as modified by van Slyke and Hiller (1947). Vomitus, gastric aspirate and random samples of ileostomy fluid were similarly analyzed, the ileostomy samples usually being obtained between 9 a.m and I I a.m. Sodium, potassium and chloride of concentrations in plasma were determined as above and the $\mathrm{CO}_{2}$ combining power by the volumetrie method of van Slyke.

\section{Case Summaries}

Case 1. Male, aet. 29 years. Ulcerative colitis. Total colectomy with terminal ileostomy performed on January 16.

Progress very satisfactory for four days. Vomiting began on January 20. Pulse rate rose to between 120 and $140 / \mathrm{min}$., but the blood pressure did not fall and the peripheral circulation remained adequate. On January 30 signs of intestinal obstruction developed, presumably due to adhesions. On February I $_{5}$ semi-solid faeces were passed from the ileostomy for the first time and further progress was uneventful.

The salient features of the fluid and electrolyte exchange are shown in Figs. $I$ and 2 and Table $I$. During most of the period of study the urine $\mathrm{Na}: \mathrm{Cl}$ ratio was low except for the days when the volume of fluid lost by vomiting and gastrointestinal suction was at its highest.

Comment. During the first 30 days after operation it was difficult to maintain a satisfactory fluid balance. The loss from the ileostomy measured 43.61 . and almost 561 . of fluid were given intravenously. Sodium chloride given intravenously 


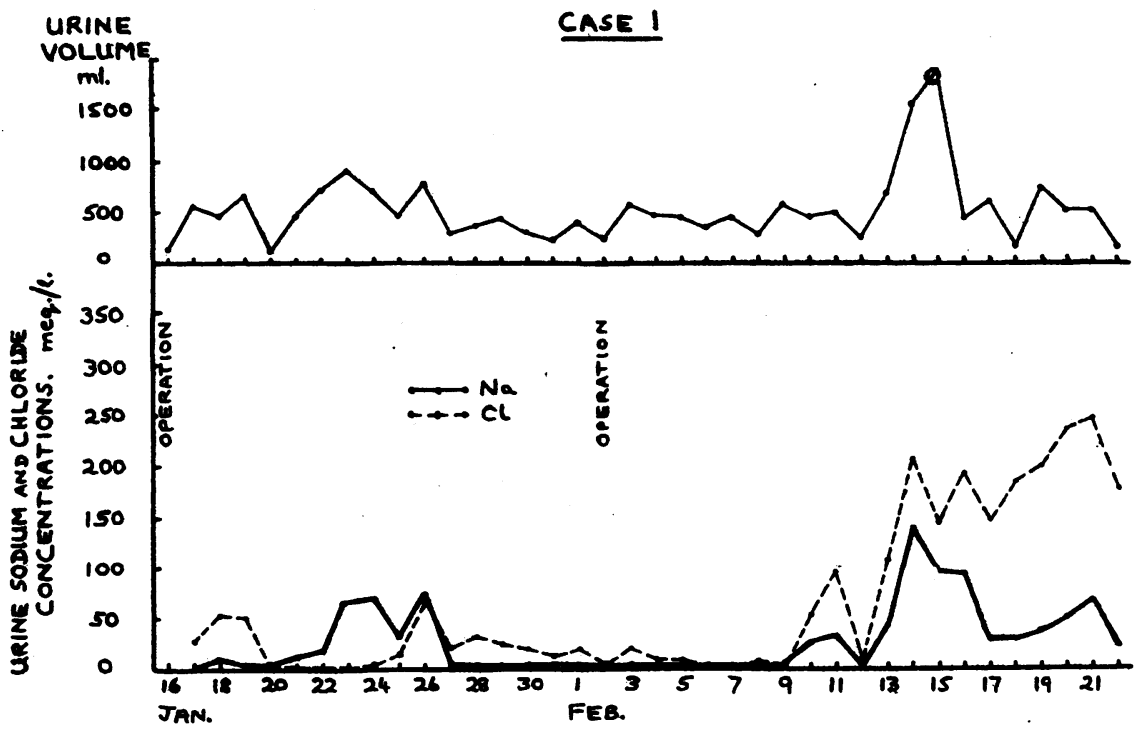

Fig. 1.- Showing urine volume and sodium and chloride concentrations in the urine. Attention is directed to the low urinary volume and to the extremely low concentrations of sodium and of chloride during the period from January 27 to February 9.

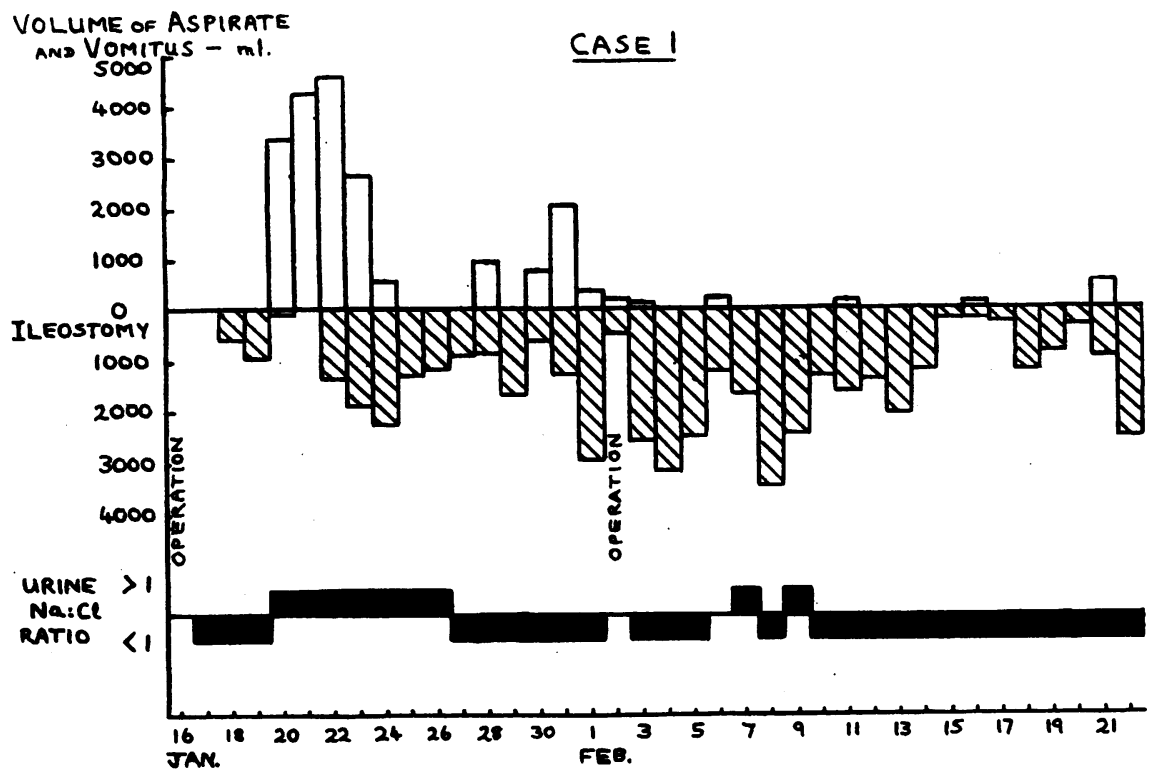

Fig. 2.- Showing volume of fluid lost from the ileostomy and from the upper gastrointestinal tract. The urine $\mathrm{Na}: \mathrm{Cl}$ ratio is depicted diagrammatically. A ratio greater than $I$ is plotted above the line and a ratio of less than $I$ below. During the period from January 19 to 25 , when aspiration and vomiting were copious, the ratio was greater than I. The ratio greater than $I$ on February 7 and 9 are without significance as the urinary concentrations of sodium and chloride were negligible. 
TABLE I

Case I-Details of Fluid and Electrolyte losses and Replacement

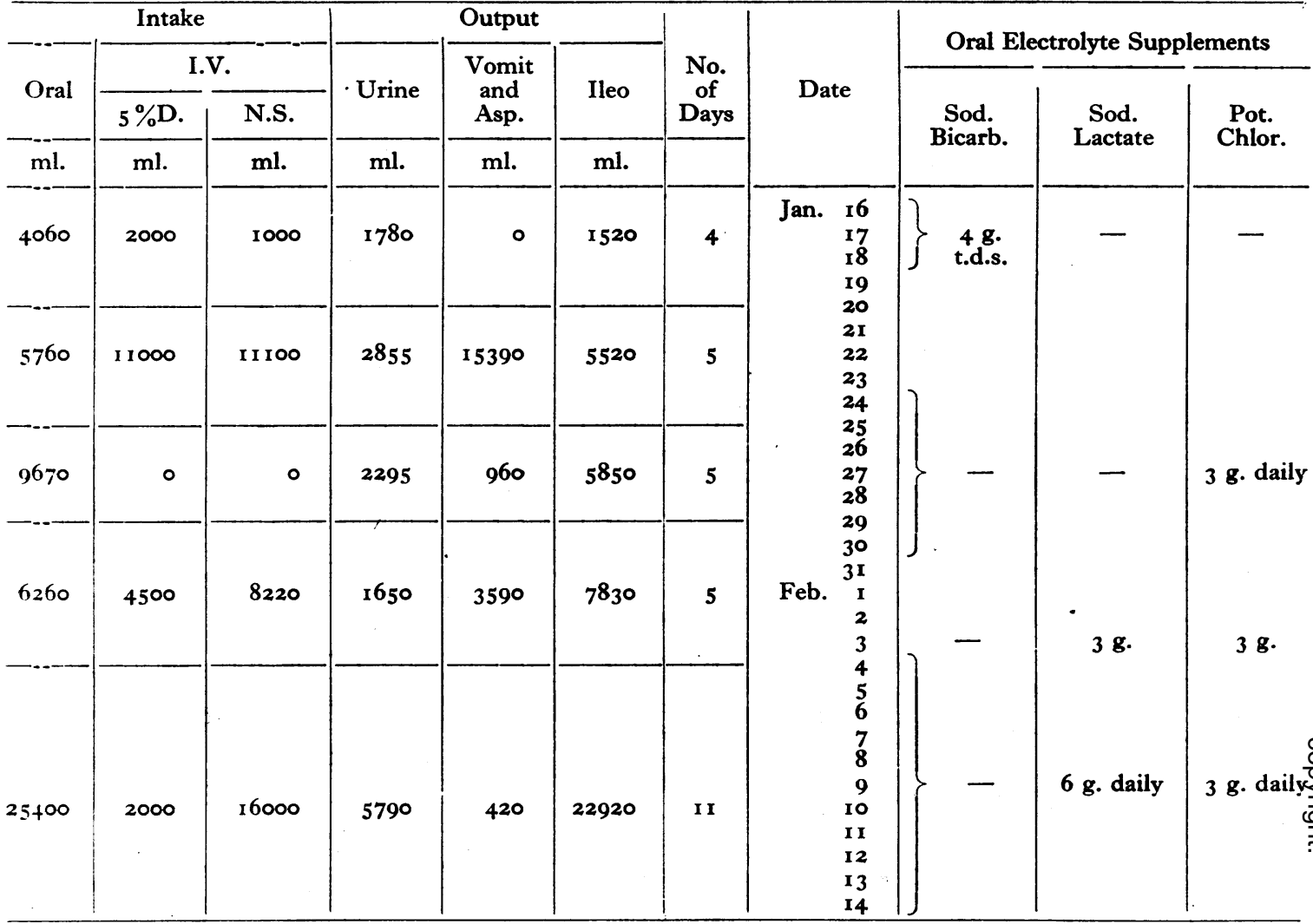

Total Intake: $106,970 \mathrm{ml}$.

Total Output:

$78,370 \mathrm{ml}$.

Balance in 30 days : $28,600 \mathrm{ml}$. (av. $950 \mathrm{ml}$./day).
[NoTE $-5 \% \mathrm{D} .=5 \%$ dextrose in distilled water.

N.S. $=0.9 \%$ sodium chloride in distilled water.] totalled $325 \mathrm{~g}$. and almost $6,600 \mathrm{mEq}$. of sodium were given parenterally or as oral supplements.

Case 2. Male, aet. 54 years. Ulcerative colitis. Total colectomy and terminal ileostomy performed on November 28.

Progress satisfactory until December 9, when the patient became very anxious and exhausted; blood pressure $104 / 80 \mathrm{~mm}$. $\mathrm{Hg}$, pulse rate $136 / \mathrm{min}$.

On the morning of December 13 he was very collapsed, cold, sweating and cyanosed and could scarcely speak; blood pressure $100 / 80 \mathrm{~mm}$. Hg, pulse rate $140 / \mathrm{min}$. One litre of 6 per cent. dextran in 1.8 per cent. sodium chloride was given with marked improvement in the peripheral circulation.

On December 17 the state of the peripheral circulation again gave cause for anxiety but after 2 1. of $M / 6$ sodium lactate the blood pressure stabilized at about $130 / 80 \mathrm{~mm}$. $\mathrm{Hg}$ and the pulse rate fell to between 100 and $110 / \mathrm{min}$.

Intestinal obstruction, again presumably due to adhesions, developed on December 31, but subsided without operation.

Changes in the urine $\mathrm{Na}: \mathrm{Cl}$ ratio are shown in Fig. 3. On December I6, when there was a state of peripheral failure, the ratio was as low as 0.02 (sodium 3.I mEq./l., chloride $146.0 \mathrm{mEq} . / 1$.) while during the period of intestinal obstruction the ratio was greater than unity (ratio on January $I$, 2.55).

Comment. The outstanding feature in this case was the degree of shock and peripheral failure during the period from December I I to December 22, finally overcome by the administration of sodium lactate intravenously.

Case 3. Female, aet. 35 years. Diarrhoea and 
CASE 2

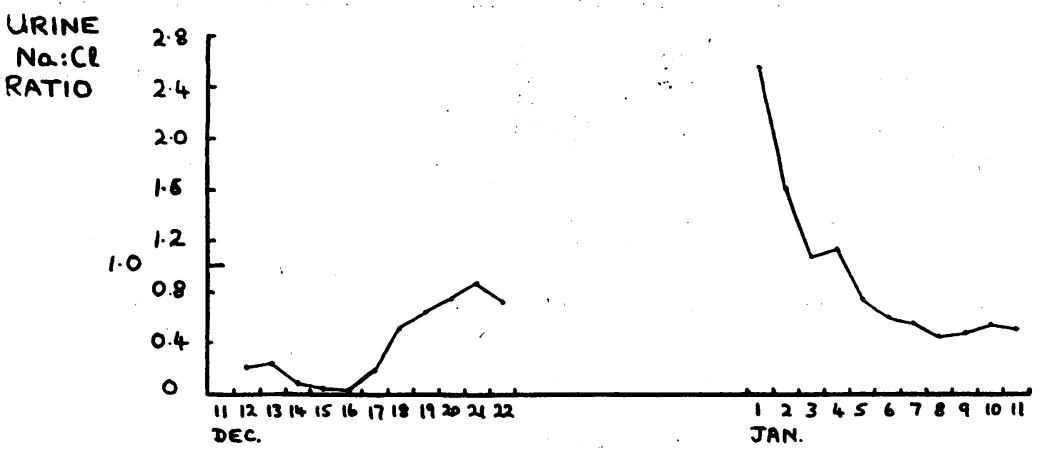

Fig. 3.- Showing changes in the urine $\mathrm{Na}: \mathrm{Cl}$ ratio. During the first period, from December 12 to 22 , the ileostomy was the only source of extra-renal fluid and electrolyte loss (apart from sweat) and the urine $\mathrm{Na}: \mathrm{Cl}$ ratio was low. When upper gastro-intestinal losses were copious from January I to 3 , the ratio of sodium to chloride in the urine was greater than $\mathrm{I}$.

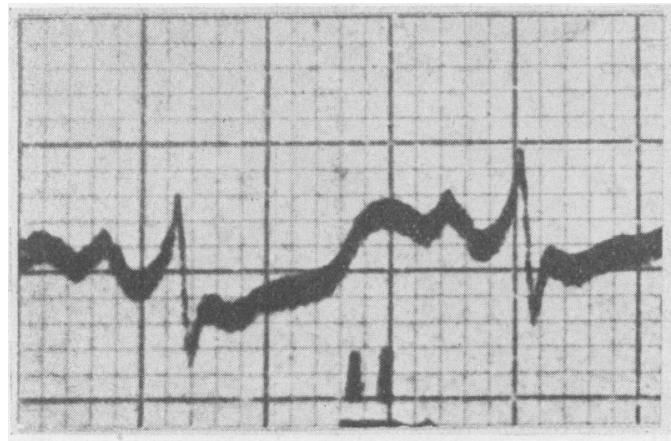

A

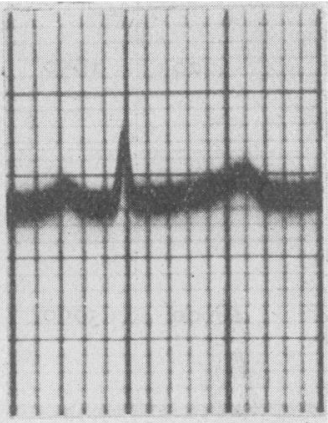

$B$

Fig. 4.- Case 3. Electrocardiograms, lead II. (A) On February 20, showing sinus tachycardia, prolonged QT ratio and depressed ST segments. The ST segment was depressed in all leads except $V_{3}$, while the $T$ wave was inverted in lead $I$ and biphasic in leads $V_{3}, V_{5}$ and VF. (B) On February 23. This E.C.G. was reported as being within normal limits.

faecal incontinence following total colectomy and ileosigmoidostomy performed two years previously. Terminal ileostomy and closure of rectal stump on January 2.

Progress from January 2 to February 12 was relatively smooth apart from occasional vomiting and gastric aspiration. The ileostomy was refashioned on February I3. The blood chemistry before this operation is shown in Table 2, but the results had not been known. After the refashioning of the ileostomy the patient received 5 per cent. dextrose intravenously together with fluids by the oral route.

During the night of February 19-20 the patient was delirious and next morning, when seen by the metabolic unit for the first time, she was totally disorientated, could hardly move in bed, had soft, slurred speech and absent deep reflexes with a very poor grip. There was no oedema. Bowel sounds were present and there was no vomiting. Pulse rate $100 / \mathrm{min}$. An E.C.G. (Fig. 4) was interpreted as showing evidence of potassium deficiency. Examination of the blood on February 20 showed: 욱 $\mathrm{Na} 107.0 \mathrm{mEq}$./1., $\mathrm{K}$ 3.I mEq./1., $\mathrm{CO}_{2} 35.1 \mathrm{mEq}$./1., $\mathrm{Cl}_{5} 6.7 \mathrm{mEq} . / 1$., urea $49 \mathrm{mg}$. per cent.

In the course of the 22 hours from ro a.m. on $N$ February $20,1,500 \mathrm{ml}$. of dextran in $\mathrm{r} .8$ per cent. sodium chloride were given and 21 . of 5 per cent. $N$ dextrose in 0.9 per cent. sodium chloride (a total ${ }_{\omega}^{N}$ of $45 \mathrm{~g}$. of sodium chloride intravenously). In spite of the not markedly lowered plasma potassiumio concentration potassium chloride was given in $3 \mathrm{~g}$. \ doses by mouth three-hourly up to a total of $18 \mathrm{~g}$. ? By the morning of February 21 the condition of $T$ the patient had changed dramatically. She was

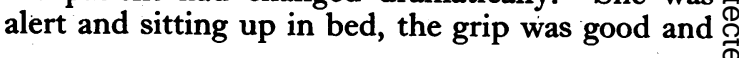


TABLE 2

Case 3-Blood Chemistry

\begin{tabular}{|c|c|c|c|c|c|c|}
\hline \multirow{2}{*}{\multicolumn{2}{|c|}{ Date }} & $\mathrm{Na}$ & K & $\mathrm{CO}_{2}$ & $\mathrm{Cl}$ & \multirow{2}{*}{$\frac{\text { Urea }}{\text { mg. } \%}$} \\
\hline & & \multicolumn{4}{|c|}{ mEq. $/ 1}$. & \\
\hline & & 125.0 & - & 36.4 & 68.4 & - \\
\hline Fed. 2 & $\cdot$ & 107.0 & 3.1 & & 56.7 & 49.0 \\
\hline Feb. 2 & & 147.0 & & 27.0 & 98.3 & 41.0 \\
\hline Feb. 25 & & 137.0 & 4.9 & $20 \cdot 3$ & 101.7 & 30.0 \\
\hline Aug. 14 & .. & 152.0 & 4.0 & 17.6 & 113.0 & - \\
\hline
\end{tabular}

the deep reflexes had returned. The blood chemistry had returned to normal (Table 2). An E.C.G. on February 23 (Fig. 4) was reported to be within normal limits. Further progress was uneventful. The blood chemistry was repeated on August I4, seven and a half months after formation of the ileostomy and at this time she was well but stated that she occasionally experienced a craving for salt. On this occasion the sodium and chloride concentrations were elevated and the $\mathrm{CO}_{2}$ combining power was decreased.

Comment. Only the results during the period of recovery from the acute episode are presented, from Io a.m. on February 20 to 8 a.m. on February 23 ('Table 3). Complete balance studies were not carried out during the recovery period. The losses in the urine were measured and losses in the ileostomy fluid estimated from random samples气 The intakes of sodium, potassium and chloride byz the intravenous route or as oral supplements were known, and since the oral intake on February 26 . was limited to milk and water it is possible to calculate the electrolyte balances on that date with a sufficient degree of accuracy to permit some interpretation of the biochemical changes which had occurred.

On February 20 the patient was grossly de- $\stackrel{\mathbb{}}{2}$ pleted of sodium and chloride and presented the classical picture of potassium deficiency. Between February 20 and 21 . the plasma chloride con:centration rose from $56.7 \mathrm{mEq}$. $/ 1$. to $98.3 \mathrm{mEq}$. $/ \mathrm{Lew}_{\mathrm{ou}}$ in the presence of a positive chloride balance of almost $900 \mathrm{mEq}$. If all this chloride had beeg retained in the plasma and extracellular fluif. without alteration of their total volume, the volume of plasma and extracellular fluid togethej on February 21 must have measured about 221. an unlikely figure. The combined plasma and extracellular fluid volumes on February 20 almosf certainly did not exceed ro l., containing approxi mately $600 \mathrm{mEq}$. of chloride. If no chloride entered the cells during recovery the total of abouf $1,500 \mathrm{mEq}$. on February 21 could have beef accommodated in 151 . of plasma and extracelludaro fluid. Thus, within 24 hours, the volumeog

TABle 3

CASE 3

(a) Fluid Balance During Recovery

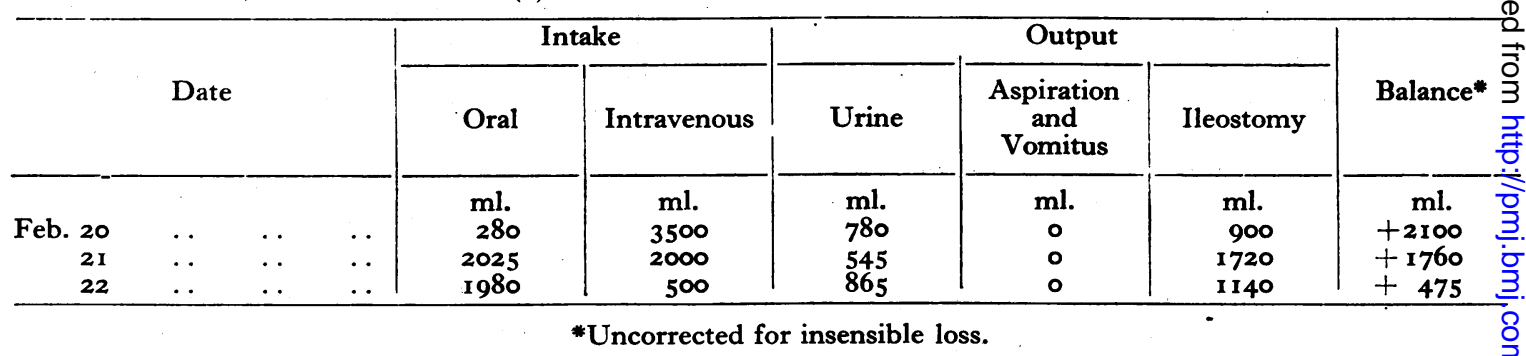

(b) Electrolyte Intake and Output Data During Recovery

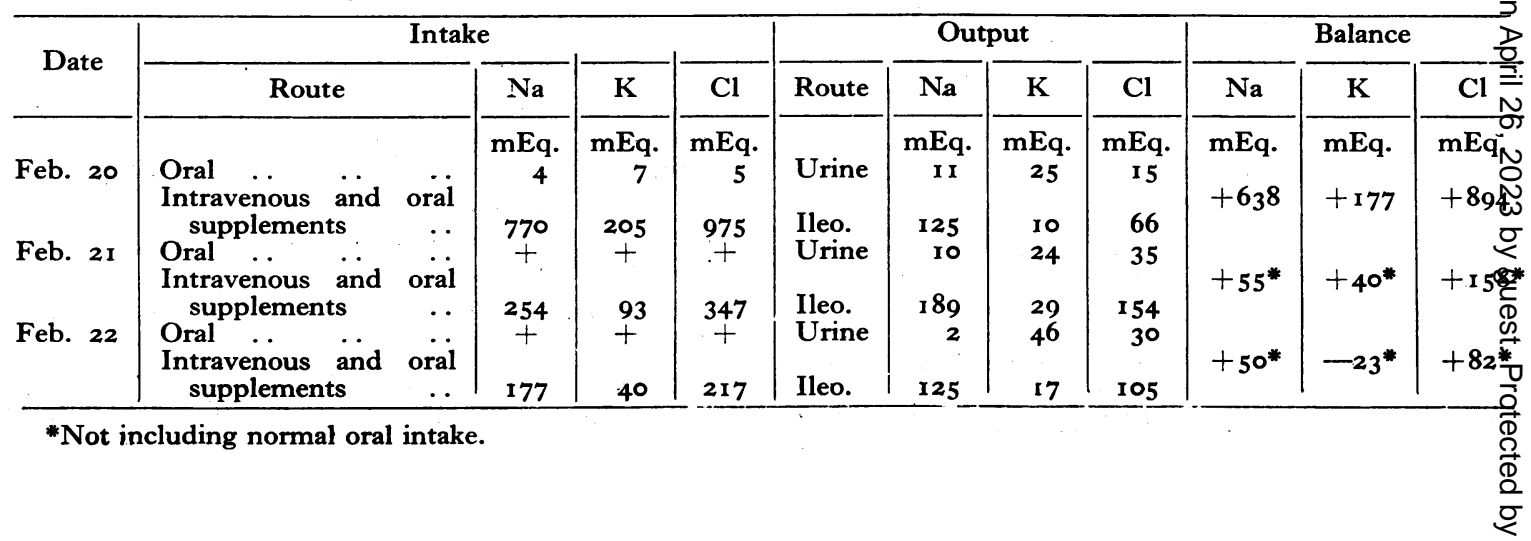




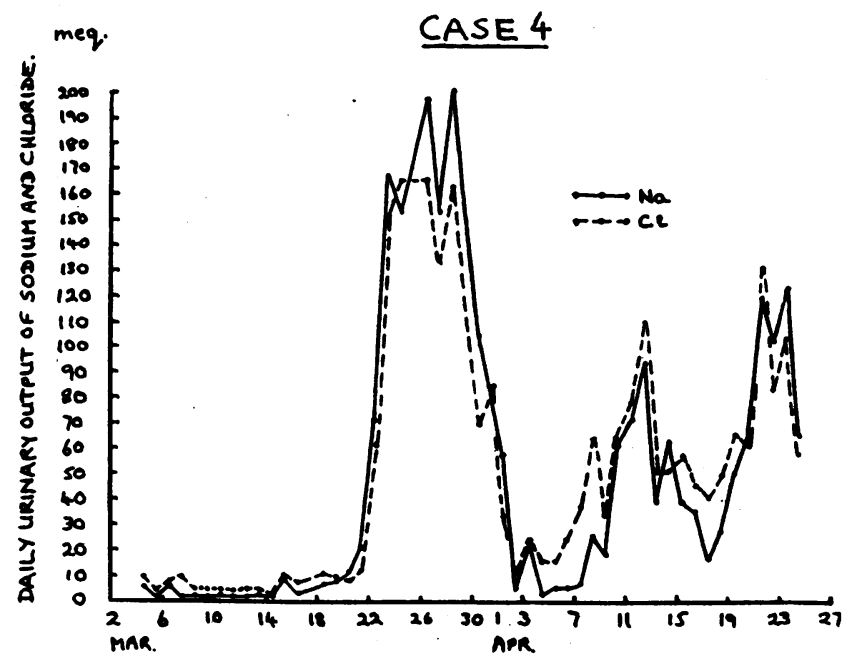

Fig. 5.-Showing urinary output of sodium and chloride. Excretion of the two ions closely paralleled each other.

plasma and extracellular fluid may have risen by as much as 51 , while the fluid balance was positive by only I l., allowance having been made for insensible loss. The difference of about 41 . "can only have come from an intracellular source. Intracellular oedema might also be expected from the degree of hypotonicity of the plasma, and therefore of the extracellular fluid.

Case 4. Female, aet. 26 years. Ulcerative colitis. Total colectomy and terminal ileostomy performed on March 5 .

On March 12 a wound abscess was incised and drained and on April 2 the rectal stump was excised by the perineal route.

Between March 9 and April 24 the oral intake of sodium chloride and sodium citrate was varied. The sodium intake, in excess of the sodium content of the standard diet, is shown in Fig. 6, together with the urinary sodium output.

Throughout the period of study (March 3 to April 24) the patient showed no clinical evidence of electrolyte imbalance. Blood chemistry data during and after the period of investigation are presented in Table 4. The patient returned to work early in May and when seen in May and

$$
\begin{gathered}
\text { Table } 4 \\
\text { Case } 4 \text {-Blood Chemistry } \\
\text { mEq./l. }
\end{gathered}
$$

\begin{tabular}{|c|c|c|c|c|c|c|}
\hline \multicolumn{3}{|c|}{ Date } & $\mathrm{Na}$ & $\mathbf{K}$ & $\mathrm{CO}_{2}$ & $\mathrm{Cl}$ \\
\hline April 14 & .. & & 138.0 & - & 18.0 & $93 \cdot 3$ \\
\hline April 27 & . & . & 143.0 & 4.6 & $24 \cdot 5$ & 105.1 \\
\hline May 5 & $\cdots$ & $\cdots$ & 147.0 & 4.6 & 21.9 & 112.0 \\
\hline Aug. 8 & $\cdots$ & . & 158.0 & 4.0 & & 109.0 \\
\hline
\end{tabular}

August had no symptoms although the blood chemistry was not normal.

Comment. An average of $790 \mathrm{ml}$. of fluid was lost daily from the ileostomy, with average concentrations of sodium, potassium and chloride of 124.0, 10.3 and 61.4 mEq./l. respectively. Thus the average daily loss of sodium in excess of chloride was about $50 \mathrm{mEq}$. Despite this, and by the use of sodium citrate, the urinary sodium and chloride concentrations parallelled one another closely (Fig. 5). In general, too, changes in the urinary sodium excretion also paralleled the changes in the amount of sodium given in addition to the standard diet (Fig. 6).

Case 5. Female, aet. 54 years. Ulcerative colitis. Total colectomy, perineal excision of rectum and terminal ileostomy performed on February 9.

The ileostomy acted on the day following operation and an average of $430 \mathrm{ml}$. a day was lost by this route between February ro and February 23 . (Average sodium concentration $126.0 \mathrm{mEq}$./l., average chloride concentration $62.3 \mathrm{mEq} \cdot / 1$.)

Sodium citrate administration by mouth was begun on February 12, $8 \mathrm{~g}$. daily until February I7, when the dose was reduced to $4 \mathrm{~g}$. a day. Administration of sodium citrate was discontinued on February 23. Progress was completely uneventful and the patient was discharged from hospital on February 28.

Comment. The daily outputs of sodium and chloride in the urine are shown in Table 5, together with the amounts of sodium citrate given by mouth. With the exception of the first four 


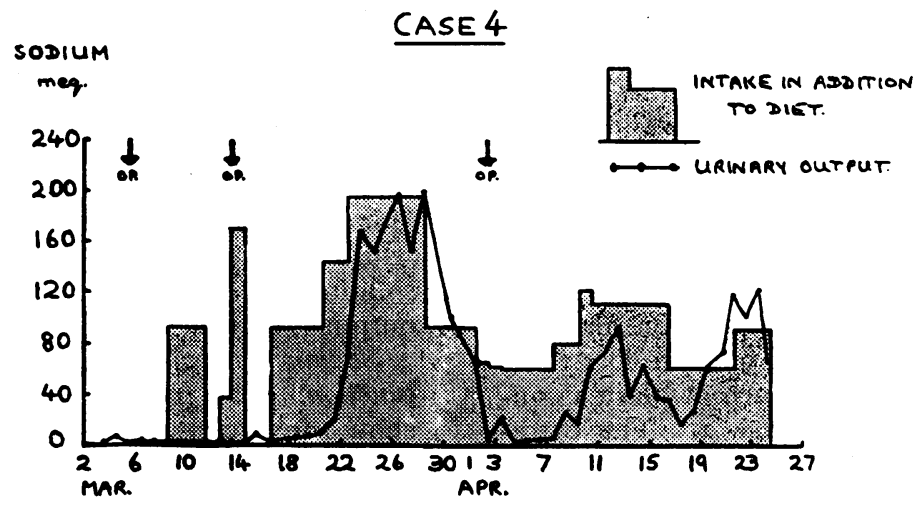

FIG. 6.-Showing intake of sodium as sodium chloride or sodium citrate in addition to the standard diet, and urinary loss of sodium. It will be seen that in general the changes in urinary output follow the changes in intake.

TABle 5

Case 5-Urine Data and Electrolyte Therapy

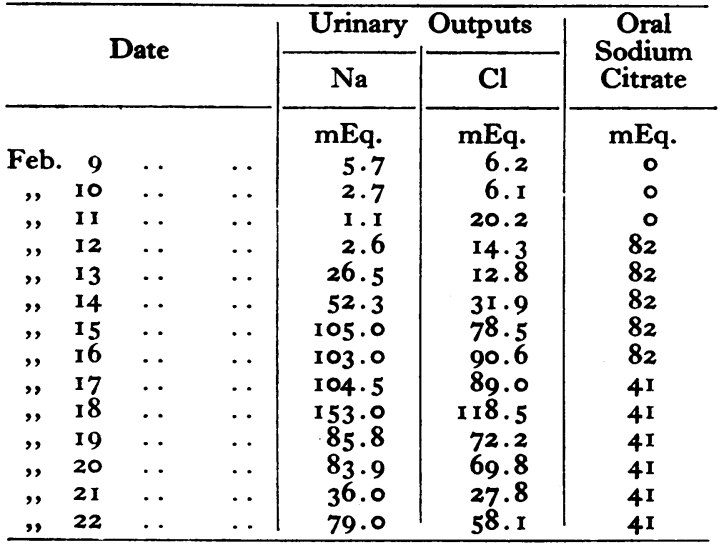

days after operation the urinary sodium concentration was greater than the chloride concentration.

\section{Discussion}

Electrolyte imbalance may occur in patients with recent ileostomies as a result of the large quantities of water and electrolytes which may be lost through the ileostomy, and of the vomiting which may occur or of the gastro-intestinal aspiration which may be required.

Fluid balance. In Case $\mathrm{I}$ it was difficult to prevent the development of severe dehydration. A total of 55.8 1. of fluid was given intravenously during the first month after operation, while 43.6 1. were lost from the ileostomy in this same period. The maximum volume of fluid lost from the ileostomy during any one 24-hour period was $3,500 \mathrm{ml}$., less than the daily loss of 41 . or more which has been observed by Warren and McKittrick (1951). When abnormal losses occur at this rate particular attention must be paid their precise replacement, and failure to do $\$ Q$ jeopardizes the chance of recovery.

Fortunately not all ileostomies lose fluid in this way in the early post-operative period, and the patient in Case 5 was discharged from hospital only 19 days after operation, the ileostomy lo never exceeding $690 \mathrm{ml}$. in any one 24 -hour period.

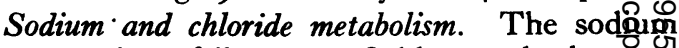
concentration of ileostomy fluid exceeds the epncentration of chloride by approximately $55 \mathrm{mE}$, average concentrations of the two ions being T and $68 \mathrm{mEq}$./1. respectively. A normal diet pro. vides between 4 and $8 \mathrm{~g}$. of sodium chloride daik ( 70 to $140 \mathrm{mEq}$. each of sodium and chloride), and in the absence of electrolyte losses by other rout $\overrightarrow{\delta s}$ the whole of the normal daily intake of chloride may be lost in under 21 . of ileostomy fluid whereas the whole daily intake of sodium may lost in less than $\mathbf{I . 2} 1$.

The chloride content of the urine, determined by the method of Fantus (1936) provides no diregt indication of the state of sodium metabolism and is of little practical value and may even be mis leading if taken as a guide in the management of patients in whom the sodium loss exceeds the chloride loss (Marriott, I95I; Lockwood ant Randall, r949; Randall et al., 1950). The chloriese content of the urine of the patient in Case 2 of December 13,14 and 15 averaged $135 \mathrm{mEq}$. ht (equivalent to $8 \mathrm{~g}$. of sodium chloride/litre of urime by the Fantus method) although virtually 100 sodium was excreted in the urine on these thre days. It is when considerable upper gastre intestinal tract losses occur, with a chloride conte $\overline{\text { t }}$ t exceeding the sodium content, that the Fantus test may be of some practical value, as in the secont period of study of the patient in Case 2. 
It is important to remember that the sodium requirements of the body may differ from the chloride requirements (Gamble and Ross, 1924; Lockwood and Randall, r949; Goldzieher and Stone, 1949). Determination of the plasma sodium concentration is not infallible in detecting sodium deficits, for the plasma sodium concentration may be maintained at the expense of the plasma and extracellular fluid volumes (Gamble et al., I923; Stewart and Rourke, 1942). When large amounts of extracellular electrolyte (sodium) are lost there may, however, be no maintenance of plasma concentrations, as occurred in Case 3. The extracellular osmotic pressure is sacrificed but the volume of the total body water is maintained (Darrow and Yannet, 1935; McCance, r936). Sodium is necessary for the maintenance of plasma and extracellular volumes and a deficit of sodium, as in Case 2, is usually associated with collapse and peripheral circulatory failure, although McCance did not observe any change in resting pulse rate or blood pressure in normal subjects who were depleted of salt. Sodium is probably of greater importance to the individual than chloride (Gamble and Ross, 1924), for sodium cannot be replaced by any other ion, whereas a deficit of chloride may to some extent be made good by an increase in bicarbonate.

Absorption of sodium by the bowel. Since the requirements of sodium salts by patients with ileostomy seemed to be very considerable, an attempt was made in Case 4 to assess the efficiency of sodium absorption by the bowel. If the absorption of sodium and chloride were impaired, the provision of additional sodium chloride by the oral route would lead to an increase in the volume of fluid lost from the ileostomy, since the fluid lost from intestinal fistulae or as a result of diarrhoea has a chloride content lower than plasma (Coller and Maddock, r940), and a sodium concentration equal to or less than that of plasma (Peters, r940).

With the exception of the periods immediately after the three operations in Case 4, when sodium and chloride were normally retained, the amount of sodium excreted in the urine ran approximately parallel to that amount administered by mouth as sodium citrate or sodium chloride, which suggests that, in this case at least, there was no interference with sodium absorption.

Urine $\mathrm{Na}: \mathrm{Cl}$ ratio. A low $\mathrm{Na}: \mathrm{Cl}$ ratio in the urine occurs in patients in whom extrarenal losses of sodium are greater than those of chloride (Denton et al., I95I; Randall et al., 1950). Administration of sodium citrate, as in Cases 4 and 5 , will help to maintain a urinary $\mathrm{Na}: \mathrm{Cl}$ ratio close to $\mathrm{I}$, indicating that losses of sodium in excess of chloride by routes other than urinary are being adequately replaced, and that there is little risk of disturbance of acid-base balance, although LeQuesne (1953), discussing possible disturbances of acid-base equilibrium in the presence of disproportionate extrarenal losses of sodium and chloride, states that sodium chloride administration, along with enough water, will allow the kidneys automatically to restore the acid-base balance by appropriate differential excretion of sodium and chloride ions, provided the urinary output is satisfactory.

Sodium and chloride metabolism and bowel function. The patients in Cases 4 and 5 did not show any clinical evidence of post-operative electrolyte complications, although the amounts of sodium and chloride excreted in the urine on some days was low. The volume of fluid lost from the ileostomies of these patients was never sufficient to lead to dehydration or sodium deficiency. Perhaps early and adequate provision of additional sodium to these patients may have been a factor in preventing the development: of the gross ileostomy diarrhoea seen in Cases $I$ and 2.

Sodium chloride deficit may be accompanied by diminished activity of intestinal muscle under experimental conditions (Streeten, 1950), and ileus, abdominal distension and vomiting feature among the symptoms of salt deficiency (McCance, 1936). The patient in Case 3 did not show paralytic ileus or other sign of disturbance of gastro-intestinal function although the plasma sodium concentration was only $107 \mathrm{mEq} / \mathrm{l}$. and the chloride concentration $56.7 \mathrm{mEq}$. $/ 1$. The obstructive signs in the first two patients may have been partly paralytic rather than wholly adhesive in nature as was thought at the time.

Potassium metabolism. The management of potassium exchange in patients $I$ and 2 did not prove difficult. Potassium chloride was given by mouth in both cases as prophylaxis against the development of potassium deficiency. Neither case showed any clinical evidence of potassium deficiency.

The profound weakness, loss of reflexes, alkalosis, low serum potassium concentration and E.C.G. findings of the patient in Case 3 on the morning of February 20 supported a diagnosis of potassium deficiency, but during recovery there was a positive balance of only about $200 \mathrm{mEq}$. of potassium with elevation of the plasma potassium concentration from 3.1 to $6.2 \mathrm{mEq}$. $/ 1$. Although there was no evidence of peripheral circulatory failure or laxity of the skin, there were some symptoms of salt deficiency, namely mental confusion, coma, weakness and low sodium and chloride concentrations in the plasma. On February 20 the plasma and extracellular fluid were hypotonic and, as has been shown, up to $4 \mathrm{l}$. of fluid may have been withdrawn from the intracellular phase into 
the plasma and extracellular fluid during recovery. The clinical picture on February 20 was similar to that of water intoxication described by Wynn and Rob (1954).

Even in the absence of any gross deficit of potassium an increase in the intracellular fluid volume must be accompanied by a decrease in the intracellular concentration of potassium, and it is probable that the symptoms and signs of potassium deficiency in this case reflected a fall in the intracellular concentration of this ion rather than a true gross deficit. Black and Milne (1952a) produced potassium deficits of 268 and $289 \mathrm{mEq}$. in normal individuals but with none of the classical features of potassium deficiency, and they calculated that in their cases the volume of intracellular fluid probably decreased (Black and Milne, 1952b). If this were the case the intracellular concentration of potassium would tend to be maintained, even in the presence of some deficit in the total body potassium. Similarly, rapid rehydration of dehydrated patients may produce symptoms of a potassium deficiency due to lowering of the intracellular potassium concentration (Randall et al., 1949).

No potassium chloride was given to the patients in Cases 4 and 5 and neither of these showed any clinical evidence of potassium deficiency.

Adaptation of the ileostomy. Adaptation of the ileostomy usually develops over a period of several weeks after operation (Lahey, 1950b; Warren and McKittrick, 195 I), with decrease in the volume of fluid lost and in the concentrations of sodium, potassium and chloride in it (Lockwood and Randall, 1949). Complete adaptation may, however, develop only slowly. Two of the first four patients, followed up for between two and seven and a half months, showed raised sodium and chloride concentrations in the plasma and it is possible that a temporary state of equilibrium may have been reached in a mild state of dehydration. Apart from the abnormal blood chemistry both patients were well.

\section{Summary}

I. Fluid and electrolyte exchange were investigated in five patients with terminal ileostomies.

2. In the immediate post-operative period it may be difficult to maintain a satisfactory state of hydration.

3. Sodium deficiency is very liable to develop because the sodium content of ileostomy fluid is greater than that of chloride.

4. Treatment with sodium citràte by mouth should be begun as soon as possible after operation. Large amounts may be required, together with additional sodium chloride if the ileostomy is very active:
5. Chloride deficiency was observed in one case together with sodium deficiency.

6. Absorption of sodium from the bowel was investigated in one case and appeared to be unimpaired.

7. True potassium deficiency did not occu叞 Two cases received potassium chloride prophylac:tically and two did not receive any supplementary potassium. None of the patients in these fou cases showed evidence of potassium deficiency.

8. A clinical picture identical with that of potassium deficiency was observed in one patienţ, in whom there existed a gross deficit of sodiun and chloride, with intracellular oedema, but onlyt a relatively smail potassium deficit.

\section{BIBLIOGRAPHY}

BLACK, D. A. K., and MILNE, M.D. (I952a), Lancet, i, 244. BLACK, D. A. K., and MILNE, M. D. (1952b), Clín. Sci., r1, 39خు BLIXENKRONE-MOLLER, N: (1950), Acta chir. scand., 99, $23 \%$ CAVE, H. W. (1946), Ann. Surg., 124, 716.

CAVE, H. W., and NICKEL, W. F. (1940), Ibid., 112, 747. ڤ COLLER, F. A., and MADDOCK, W. G. (1940), Surg. Gyne욕
Obstet., 70, 340. COUNSELL, P. B., and GOLIGHER, J. C. (1952), Lancet, ii. I045.

DARROW, D. C. (1945), F. Pediat., 26, 519.

DARROW, D. C., and YANNET, H. (1935), f. clin. Invest., 14, 266.. DENTON, D. A., WYNN, V., MCDONALD, I. R., and SIMB S. (I951), Acta med. scand. Suppl. $26 \mathrm{r}$.

FANTUS; B. (1936), J. Amer. med. Assn., ro7, 14.

FERGUSON, L. K., and WELTY, R. F. (1947), Surg. Clin Amer., 27, 1427.

GAMBLE, J. L., and ROSS, S. G. (1924), f. clin. Invest., I, $40 \frac{2}{b}$

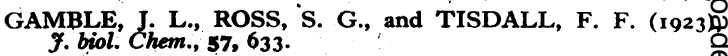

GOLDZIEHER, J. W., and STONE, G. C. H. (1949), F. clirb Endocrin., 9, 368.

HARDY, T. L., BROOKE, B. N., and HAWKINS, C. F. (r949) Lancet, ii, 5.

LAHEY, F. H. (1950a), Surg. Clin. N. Amer., 30, 893.

LAHEY, F. H. (1950b), Rev. Gastroenterol., 17, 723.

LAHEY, F. H. (1951), Ann. Surg., 133, 726.

LEQUESNE, L. P. (1953), 'Fluid and electrolyte balance (wate옥 balance) and nutrition in surgical patients,' in 'The Management of Abdominal Operations,' R. Maingot (ed.), London:Lewis, p. $22 \mathrm{I}$.

LOCKWOOD, J. S., and RANDALL, H. T. (1949), Bull. .N. Acad. Med., 25, 228.

MCCANCE, R. A. (1936), Lancet, i, 823.

MARRIOTT, H. L. (1950), 'Water and salt depletion,' Oxford? Blackwell.

MHCHAEL, M. A. (r95 I), Postgrad. Med., 9, 340.

NADAL, J. W., PEDERSEN, S., and MADDOCK, W. G. (194t F. clin. Invest., 20, 691.

PETERS, J. P. (1940), Ann. Surg., I12, 490.

RANDALL, H. T., HABIF, D. V., and LOCKWOOD, J. N (1950), Surgery, 28, 182.

RANDALL, H. T., HABIF, D. V., LOCKWOOD, I..S., and

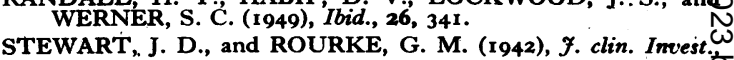
2I, 197 .

STREETEN, D. H. P. (1950), Surg. Gynec. Obstet., 91, 421. VAN SLYKE, D. D., and HILLER, A. (1947), F. biol. Chem 167, 107.

WARREN, R., and MCKIT'TRICK, L. S. (195I), Surg. Gyned. Obstet., 93, 555.

WELCH, C. S., MASSON, J. C., and WAKEFIELD, E. G. (1937) Ibid., 64, 617.

WYNN, V., and ROB, C. G. (1954), Lancet, $1,58 \%$. 